\title{
Articles
}

\section{Partners in Learning? A Qualitative Study of the Intimate Relationships of Partnered Mature Students in Postsecondary Education}

Tricia van Rhijn, University of Guelph

Sarah Hunter Murray, Winnipeg, Manitoba

Robert C. Mizzi, University of Manitoba

\begin{abstract}
Mature postsecondary students face unique challenges in negotiating both academic and familial responsibilities beyond those faced by their traditional-aged peers. This study examined the bidirectional influences between intimate relationships and postsecondary study. Researchers conducted 28 semi-structured phone interviews with heterosexual, cisgender, partnered mature students attending universities in southern Ontario, Canada. Through a thematic analysis, the research indicated that school had a number of negative impacts on mature
\end{abstract}

\section{Résumé}

Les étudiants majeurs aux études postsecondaires doivent affronter des défis uniques quand vient le temps de négocier les responsabilités académiques et familiales qui vont au-delà de celles que doivent affronter leurs pairs, à l'âge plus traditionnel. Cette étude examinait les influences bidirectionnelles entre les relations intimes et les études post-secondaires. Les chercheurs ont mené 28 entrevues téléphoniques semi-structurées avec des étudiants majeurs hétérosexuels, cisgenres et en couple fréquentant l'université dans le sud de I'Ontario, au Canada. Par 
students' relationships; however, school also had some positive impacts. Intimate relationships were also said to have an impact on academic success. Mature students with supportive partners described being able to focus on school and perform better, while students with less supportive partners described difficulties allotting the time required for school. The article recommends that postsecondary educational institutions acknowledge the unique challenges faced by partnered mature learners and offer targeted support services. une analyse thématique, la recherche indique que l'école a eu nombre d'effets négatifs sur les relations d'étudiants majeurs; toutefois, l'école a aussi eu quelques effets positifs. II y est aussi dit que les relations intimes ont des répercussions sur la réussite académique. Les étudiants majeurs dont le partenaire appuie les études ont décrit pouvoir se concentrer sur leurs études et mieux performer, tandis que les étudiants dont le partenaire apporte moins son soutien ont décrit avoir des difficultés à consentir le temps requis à leurs études. L'article recommande que les institutions de formation post-secondaire reconnaissent les défis uniques que doivent affronter les apprenants majeurs en couple, et offrent des services de soutien ciblés.

Keywords: mature students, postsecondary education, intimate relationships, academic success, educational administration

Given the need for highly qualified, productive workers and the benefits that stem from attaining a higher education, mature students represent a key source of human capital to increase postsecondary attainment rates (Kerr, 2011). Accordingly, the number of individuals returning to seek higher education after establishing a career and starting a family is growing steadily (Giancola, Grawitch, \& Borchert, 2009). Defined as postsecondary students aged 25 and older (MacFadgen, 2008), mature students are a significant population in Canada, comprising 33.8\% of all postsecondary students (Statistics Canada, 2014). Mature students enrolled in full- or part-time university or college study are more likely to be female (57.5\%), and they represent 4.0\% of all adults 25 and older (Statistics Canada, 2014).

Mature students tend to be highly efficient and to have learning strategies and skills well suited for postsecondary education (PSE) (Norton, Thomas, Morgan, Tilley, \& Dickins, 1998). These strategies and skills have been attributed to mature students being more intrinsically motivated than traditional-age students (24 years or younger) due to their diverse life experiences and eagerness to succeed (Scott, Burns, \& Cooney, 1996). Yet mature students are more likely to withdraw from study than traditional students because of work demands, financial and emotional stress, family needs, and so forth (MacFadgen, 2008; Scott et al., 1996). 
Increased awareness of barriers to academic participation and efforts to reduce attrition rates for this student population are beneficial to the academic community and a broader society seeking highly qualified workers.

Generally speaking, meaningful attention to intimate partnerships, involvement in education, career development, and labour force participation are vital to social development (Diener \& Seligman, 2002); however, it is difficult to balance engagement in academic efforts with relationship needs (Meehan \& Negy, 2003). Mature students pursuing PSE face particular difficulty concurrently negotiating both academic and familial responsibilities (see Giancola et al., 2009; Scott et al., 1996; Sweet \& Moen, 2007). Given this context, the current study focuses on how being a mature student impacts intimate relationships.

\section{Mature Students and Intimate Relationships}

Transitioning to PSE can have negative consequences for intimate partner relationships. In one study of 124 female, mature students, $62 \%$ felt that their marriage was negatively impacted by returning to school (Sweet \& Moen, 2007). Negative consequences can include psychological distance between the couple and social isolation (Gilbert, 1982), as well as conflict, arguments, and being unable to resolve problems (Gold, 2006). These problems can lead to infidelity, separation, and divorce (Brannock, Litten, \& Smith, 2000; Galvin, 2006; Norton et al., 1998; Shollenberger, 2001). Experiencing this kind of relationship strain may result in reduced performance and, potentially, withdrawal from study.

Although the negative impacts school has on intimate relationships are predominate, some positive impacts have been found, including increases in self-esteem and confidence, particularly among female students (Gilbert, 1982; Norton et al., 1998; Sweet \& Moen, 2007). PSE participation has the potential to enhance intimate relationships, with some mature students reporting positive impacts from personal growth related to school attendance (van Rhijn, Murray, \& Mizzi, 2015). Overall, although some literature has examined positive and negative impacts, a better understanding is needed of the association between mature students' intimate relationships and school attendance. Understanding mature students' multiple roles helps to clarify the reasons for these positive and negative impacts.

\section{Mature Students' Multiple Roles}

Individuals combining multiple roles can experience negative impacts such as stress and strain resulting from role overload (Duxbury, Lyons, \& Higgins, 2008). Partnered mature students may be susceptible to role overload as they are typically combining several demanding and important roles (e.g., intimate relationships, school, work). Mature students commonly report lack of energy, social life, and time, in addition to financial strains, sexual dissatisfaction, and 
role strain (Brannock et al., 2000; Fuenfhausen \& Cashwell, 2013; Galvin, 2006; Gilbert, 1982; Meehan \& Negy, 2003; Norton et al., 1998; Shollenberger, 2001; Sweet \& Moen, 2007). A person experiences role strain when they feel unable to meet the demands of multiple roles (Goode, 1960). The presence of children can result in additional stress (Gold, 2006) and reduced marital satisfaction for mature students (Meehan \& Negy, 2003; Sweet \& Moen, 2007). Vaccaro and Lovell (2010) point out that there may be a common perception amongst higher education practitioners that this additional stress results in disengagement. As a result, mature female students are historically being viewed as "deficient." In addition, studying persistence among mature students, Markle (2015) found that "women with higher GPAs, with higher levels of confidence and attending school part-time were more likely to persist" (p. 275). Both of these studies suggest that resiliency and strength among adult women learners contribute significantly toward their persistence and success.

There is some evidence that the experiences of mature students in one role influence their experiences in the other. Attending school can be stressful for mature students; strains from school demands may influence the quality and quantity of time spent with intimate partners (Gold, 2006; van Rhijn et al., 2015). In a study of transferred stress between roles, mature students perceived that the greatest conflict came from school demands negatively impacting their family (Giancola et al., 2009). Further, mature university students report that feeling tired, not having enough time together, and stress negatively impacted sexual satisfaction, and perceptions of partner support impacted both partner and sexual satisfaction (van Rhijn et al., 2015). This added stress may be explained by Gouthro's (2002) assertion that "academic institutions and adult education programs become viewed as products that need to be effectively marketed" (p. 3), which overlooks the potential for students to develop the necessary skills and understandings that will enhance their quality of life. Thus, the relationship between academic struggle, success, and mature students' satisfaction is likely bidirectional in nature, and could be influenced by the increasing marketization of higher education.

Furthermore, students content in their heterosexual marriages are found to be more successful in their studies, whereas students in dysfunctional marriages are less successful (Gilbert, 1982). Similarly, those satisfied in their relationships tend to have higher grades (Shollenberger, 2001). Social support from close partners or friends influences mature students' approaches to studying (Kahu, Stephens, Zepke, \& Leach, 2014) and their academic success (Lundberg, Mclntire, \& Creasman, 2008); institutional support at the university level influences the relationships and well-being of mature students (MacFadgen, 2008). In addition, perceived support from partners is strongly related to marital satisfaction. Spouses have been found to be important sources of emotional support in partnered individuals' lives (Cramer, 2004; Huston-Hoburg \& Strange, 1986), and perceived support is more important than partner satisfaction in determining marital satisfaction (Norton et al., 1998). Social support acts to buffer stress, especially stress related to role strain and work overload (Brannock et al., 2000; Norton et al., 1998). Given that intimate partners are a key source of support (Meehan \& Negy, 2003), and that external stressors impact intimate relationship happiness (Bodenmann, Ledermann, \& Bradbury, 2007), 
it is likely that successful transition to and performance in higher education is closely related to relationships with intimate partners. Indeed, Lowe and Gayle (2007) identified the quality of support as a key influence on the success of mature learners in balancing their study, work, and family lives.

\section{Theoretical Framework}

A theoretical model of intimacy, as defined by therapist and researcher David Schnarch (2001), guides the current study. According to Schnarch (2001), intimacy can be increased when both members of a couple experience "differentiation": the ability to manage one's independence and interdependence within a relationship. Schnarch suggests that couple intimacy is fuelled by each individual's engagement in their own interests in addition to couple activities. Differentiation contrasts to couples who are "enmeshed" (i.e., whose members do not have a separate identity outside of their relationship), or couples who live almost entirely independent lives and do not allot time and attention for couple connection. For mature students, it may be that returning to school increases partner intimacy as the student pursues their own interests outside of their relationship, thereby engaging in differentiation. Alternatively, as too much independence is theorized to decrease intimacy, couples with one partner returning to school may find that they are pulled so far apart that their intimacy, and desire for sexual connection, decreases.

\section{Research Questions}

The purpose of this qualitative study was to enhance understanding of how intimate relationships are experienced by partnered mature students during their pursuit of PSE; in a broader sense, this project strove to bridge two disciplines that rarely give consideration to each other, namely the fields of adult education and intimate relationship research. This study enhances understanding of how intimate relationships may be impacted when partnered mature students attend university, in addition to how intimate relationships may foster or hinder academic success. Two research questions were investigated:

1. What is the relationship between sexual/relationship satisfaction and school-related performance when one individual in an intimate partnership enrols in postsecondary study? and

2. What supports can be provided by postsecondary institutions to address the needs of partnered mature students? 


\section{Method}

Following the institutional ethics review, this study recruited participants via email from a list of 315 volunteers from a previous study on mature students in southern Ontario postsecondary institutions (van Rhijn et al., 2015). Seventy individuals who responded were invited to complete a screening questionnaire. If the applicants were eligible, researchers conducted semi-structured interviews by phone or Skype (depending on preference), enabling contact with mature students at a variety of institutions by accommodating participants' busy schedules. Participants were provided with the interview questions ahead of time and interviews were audio-recorded. The questions focused on the role of partners, school performance, changes in intimate relationship, and impact on learning.

Twenty-eight heterosexual, cisgender mature students were interviewed (Table 1). Participants attended one of eight different universities in southern Ontario. Fifteen participants (53.6\%) attended school part-time while the remaining 13 participants were full-time. There were more female $(n=19 ; 67.9 \%)$ than male participants $(n=9)$. Participants ranged in age from 26 to $68(m=40.0)$. The majority of participants were married $(n=19 ; 67.9 \%)$, and the remaining participants either lived with their partner $(n=6)$ or were engaged to be married $(n=1)$; two participants ended their relationships between being recruited and their interview. Relationship duration for these participants (excluding Efrain, who chose not to provide their relationship duration) ranged from 1.6 to 42.4 years $(m=14.2)$. Nineteen participants had children (67.9\%).

Table 1: Participant details

$\begin{array}{lllllll}\text { Pseudonym } & \text { Gender } & \text { Age } & \begin{array}{l}\text { Full/ } \\ \text { part-time } \\ \text { study }\end{array} & \text { Relationship status } & \begin{array}{r}\text { Relation- } \\ \text { ship length } \\ \text { (years) }\end{array} & \text { Children? } \\ \text { Sharon } & \text { Female } & 26 & \text { Full-time } & \text { Living with partner } & 1.6 & \text { No } \\ \text { Marta } & \text { Female } & 27 & \text { Full-time } & \begin{array}{l}\text { Separated } \\ \text { (after starting study) }\end{array} & 4.0 & \text { No } \\ \text { Candace } & \text { Female } & 28 & \text { Full-time } & \text { Married } & 5.6 & \text { Yes } \\ \text { Lidia } & \text { Female } & 33 & \text { Part-time } & \text { Married } & 13.0 & \text { Yes } \\ \text { Elaine } & \text { Female } & 34 & \text { Full-time } & \text { Married } & 11.0 & \text { No } \\ \text { Dianne } & \text { Female } & 34 & \text { Part-time } & \text { Married } & 10.0 & \text { Yes } \\ \text { Maura } & \text { Female } & 37 & \text { Full-time } & \text { Living with partner } & 4.5 & \text { Yes } \\ \text { Ana } & \text { Female } & 38 & \text { Full-time } & \text { Living with partner } & 8.9 & \text { Yes } \\ \text { Carroll } & \text { Female } & 39 & \text { Part-time } & \text { Married } & 15.0 & \text { Yes } \\ \text { Loretta } & \text { Female } & 39 & \text { Part-time } & \text { Married } & 19.3 & \text { Yes } \\ \text { Lesley } & \text { Female } & 39 & \text { Part-time } & \text { Married } & 12.0 & \text { Yes }\end{array}$




\begin{tabular}{llrlllll} 
Pseudonym & Gender & Age & paludy & Relationship status & $\begin{array}{r}\text { Relation- } \\
\text { ship length } \\
\text { (years) }\end{array}$ & Children? \\
Rebekah & Female & 42 & Full-time & Married & 23.0 & Yes \\
Nora & Female & 43 & Part-time & Living with partner & 2.0 & No \\
Carly & Female & 48 & Part-time & Married & 18.4 & Yes \\
Carissa & Female & 48 & Full-time & Married & 22.6 & Yes \\
Hani & Female & 49 & Part-time & Living with partner & 6.0 & Yes \\
Elsie & Female & 50 & Full-time & Married & 25.3 & Yes \\
Francisca & Female & 52 & Full-time & Married & 33.2 & Yes \\
Joyce & Female & 66 & Part-time & Married & 46.8 & Yes \\
Robert & Male & 27 & Full-time & Living with partner & 5.3 & No \\
Efrain & Male & 27 & Full-time & Single & n/a & No \\
Trent & Male & 31 & Part-time & Engaged & 2.8 & Yes \\
Donald & Male & 33 & Part-time & Married & 5.7 & No \\
Raul & Male & 33 & Part-time & Married & 3.3 & No \\
Gavin & Male & 41 & Part-time & Married & 20.3 & Yes \\
Eaton & Male & 42 & Full-time & Married & 12.0 & Yes \\
Sterling & Male & 55 & Part-time & Married & 9.3 & Yes \\
Clinton & Male & 68 & Part-time & Married & 42.4 & Yes \\
\hline
\end{tabular}

The interviews were first transcribed verbatim. Then, researchers used Braun and Clarke's (2006) six steps to thematic analysis to analyze the data. Specifically, the first and second authors began by (1) reviewing the first several transcripts to become familiarized with the data. We then (2) created an initial coding scheme. Three research assistants then (3) coded the data using the coding scheme as a guideline. Some new codes were created and/or adapted to reflect the experience of all participants. Coding challenges were discussed during weekly team meetings following a consensus model, relying on strategies identified by Fernald and Duclos (2005) to facilitate a collaborative, team-based research process. After the coding was completed, all authors (4) compared and reviewed the themes, to arrive at a common understanding of the themes, which were then (5) defined and named. These themes are presented below. 


\section{Results}

The results are presented in four sections to address the research questions. The first research question was: What is the relationship between sexual/relationship satisfaction and school-related performance when one individual in an intimate partnership enrols in postsecondary study? Three sections explore the bidirectional influences between intimate relationships and postsecondary study. These sections review themes relating to (1) negative impacts on intimate partnerships, (2) positive impacts on intimate partnerships, and (3) partner relationships' impact on academic performance. The second research question was: What supports can be provided by postsecondary institutions to address the needs of partnered mature students? The fourth section presents findings relating to services mature students suggested would assist them in better preparing for, and managing, their academic endeavours. Table 2 provides an overview of the main themes and sub-themes.

\section{Table 2: Overview of themes}

\section{Research Questions}

What is the relationship between sexual/ relationship satisfaction and school-related performance when one individual in an intimate partnership enrols in postsecondary study?

\section{Themes and Sub-themes}

1. Negative impacts on intimate relationships

2. Not enough time to spend with partner

3. Decreased desire and time for intimacy

4. Conflicts with new roles or expectations

5. Positive impacts on intimate relationships

6. Increased self-esteem

7. New bonding experiences with partner

8. Relationship impact on academic performance

9. Physical or instrumental support

10. Emotional support

11. Academic support

12. Financial support

1. Increase awareness of issues unique to mature students

2. Mature student counsellors and/or mentors

3. Support groups

4. Increased ease of access to supports 


\section{Negative Impacts on Intimate Relationships}

Returning to school had negative impacts on mature students' intimate relationships, including (1) not having enough time to spend with their partner, (2) decreased desire and time for intimacy, and (3) conflicts with new roles or expectations. Each sub-theme is described below.

\section{Not enough time to spend with partner}

Twenty-three participants described that school demands reduced the amount of time they were able to spend with their partners. Nora simply stated: "There are times where he'll say I haven't seen you in days. I'm like, that's fair, we're kind of like ships in the night." Participants shared that, while their relationships were important, school assignments often took temporary priority, as they required immediate attention. Loretta said that, when choosing between school and family, school often came first.

There were a few challenges. There is a lot of time management because you have to make the time for school regardless because there is so much reading and you have so many assignments and you have to allot that time away from your family. Even if you want to do something, you kind of can't sometimes.

Hani explained that her partner did not anticipate how much time school would consume in her schedule. As a result, when she needed to attend to assignments and exams, she perceived that he felt neglected.

There were challenges. Sometimes he felt neglected, sometimes he felt that he really didn't sign up for weekends or weeks or months of not having me be available ... It was difficult for me too because it's not like I didn't want to, I just had to make that time a priority or that research a priority.

Other reasons prevented participants from spending time with their partners. Sometimes, less predictable school schedules were incompatible with partners' traditional work schedules (i.e., Monday to Friday, 9 a.m. to 5 p.m.). Sharon commented:

We just don't have time together to have that quality time together because we're both busy during the day and not seeing each other till about 5 p.m. or 6 p.m. or 7 p.m. depending on my schedule. He works full-time standard hours and depending where I am at with work and volunteering, we just don't have a lot of quality time.

\section{Decreased desire and time for intimacy}

Decreased available time alongside increased levels of school-related stress combined to have a negative impact on 14 mature students' intimacy and desire for sexual activity. Reflecting on her sex drive before starting school and now as a mature student, Maura remarked: "I guess 
the sex drive itself was like way lower than it was last year." Another participant described that sex had to drop in priority because of stress from school demands. Candace shared:

During [stressful] times we kind of put that on a back burner, our sex life will decrease around those times as well, and that's just due to my stress level and he doesn't want to, he doesn't want to approach the subject of sex during [those times] because I'm so stressed.

Similarly, Carroll shared that school was her top priority, and the associated stress often prevented her from desiring sex.

My mind is full of other stuff and I'm not in the mood. It's just not there and I'm not thinking about it. It's not on the radar. It just feels like it takes too much effort to get there. I just don't bother.

Although participants described a lack of desire or preoccupation with school over sex, some participants noted that their desire was about the same, but they found it difficult to make time to connect. Robert said, "I think the frequency definitely reduced and it wasn't necessarily for a lack of wanting, it was more just we hardly saw each other."

\section{Conflicts with new roles or expectations}

Eight participants said that attending school and allotting the time needed to focus on schoolwork reduced time available for household responsibilities. As such, some mature students described strains in their relationship when adapting to their new demands and workloads (i.e., division of labour). Carroll said:

There has been conflict around meal-making and all those types of things where I am feeling, why do I have to come home and do this? So we might have fights about who should be doing what and that kind of thing.

Another participant described how he and his wife had to navigate their simultaneous return to school alongside part-time jobs. Efrain indicated that, while he and his patner's life circumstances changed considerably, it was challenging to determine the division of household responsibilities:

She was a full-time student for the first two terms that we were together. Then summer came and I took a few courses and she was also working as a nanny ... when we started living together ... we had a dog and also had to juggle that into university and [her] work. And so, yeah, we had not very good communication of who was doing what.

Carissa described how she and her partner previously had more traditional roles; however, when she started school, she was less able to do household chores, and this was something her partner ended up having to accommodate. 
I think the biggest discussion was around who is going to do what, 'cause we tended to be more of the traditional home. Like, I did the cooking, grocery shopping, and cleaning ... He helps but it was mostly my responsibility ... Last fall when the house wasn't getting as cleaned as well as it should have been [laughter] we decided to get a cleaning lady because he was just like, "I'm busy too and I can't do it either."

\section{Positive Impacts on Intimate Relationships}

Although study participants were more likely to identify the negative impacts that attending PSE had on their relationships, most also noted some positive impacts. These included a) increased self-esteem and b) new bonding experiences with their partner.

\section{Increased self-esteem}

Fifteen participants described feeling better about themselves since enrolling in PSE. These participants were working toward a goal, which made them feel satisfied and engaged. Carroll said, "In some ways I think it's more positive because I'm happier, like I feel more fulfilled, more engaged with stuff outside of home." Joyce described feeling more productive and useful as a result of being a student. She shared, "I feel that I'm able to address issues in a more productive way ... I feel that I can talk, speak intelligently about different aspects ... I feel I'm more productive in society because I can contribute more."

Some participants discussed a sense of purpose and direction from working toward obtaining their degree. Robert said, "There is pretty big positive impact because I am working towards something that I know I will enjoy." Another participant, Donald, similarly stated:

By working on my goal and working hard at school I think it's also been pretty positive. Especially for me personally ... I find that I am happy when I see that I do well in a course and my wife is quite proud of me when I do well and that's something that kind of makes it a positive.

\section{New bonding experiences with partner}

Fifteen participants also said that attending PSE allowed for a new way of bonding and connecting with their partner. One participant described how both she and her partner decided to go to school at a later life stage, an experience that ultimately brought them closer together. Maura said:

We are both at the point where we made major changes in our academic career and our professional career. I guess for us both being at the same phase at the same time ... had a huge bonding effect on our relationship... walking the path together even though we are in slightly different fields. I guess that we share this experience makes it way easier for us to relate to each other. 
Carissa said that her learning provided fodder for conversation with her husband when she returned home, allowing for deeper, more intellectual conversations. She commented:

[We have] more intelligent conversations. Because when you get a few days at home and even the kinds of jobs I had back then when we first moved, I helped with school as I was a lunch monitor. I have always done something but it has not always been mentally stimulating. [laughter]

Sharon noticed some positive changes in her partner since she began her studies. She described feeling that it was her enrolment in PSE that was the catalyst for positive changes in him and in their relationship.

I've transferred some of the skills I've learned in school, in terms of organization, writing skills, even speaking skills, and I feel like I've actually sort of inspired him ... I'm noticing that he's even using words that l've used and he's trying to brush up on certain things in terms of keeping an agenda and schedule and to allocate and time manage certain hours of the evening to working on a business plan or this project while I'm working on my homework. I think that it's really nice he's kind of mirroring some of the work that I've been doing, some of the skills that l've been learning.

\section{Relationship Impact on Academic Performance}

The quality of participants' intimate relationships appeared to impact their academic success. Mature students who identified their relationships as satisfying and supportive indicated that their partners helped improve their school performance by providing a) physical or instrumental support, b) emotional support, c) academic support, and d) financial support. These supports helped reduce stress, allowing participants to better focus on school demands.

\section{Physical or instrumental support}

Mature students' partners provided help that eased 21 participants' experience of stress, enabling them to focus more on school knowing that the responsibilities at home were under control. Elsie said, "He would help make dinner, he would do the dishes or unload the dishwasher, or whatever while I was in class so I wouldn't have to come home and do it." Donald appreciated being able to return home to a prepared meal. He described it as not only a chore he did not need to worry about, but an action his partner engaged in that made him feel taken care of, thereby reducing his stress. He commented:

For me, it's basically after a long day of work and then classes afterwards, know[ing] that when I get home there will be food on the table. It's a very comforting thing ... physically I'm tired, but mentally, it's very comforting and I'm more relaxed and less stressed, knowing that someone is there to support me. 
Dianne shared that her partner knew when she needed to focus on school and helped out more during those times to keep their kids distracted. She described how this allowed her to focus more on school.

He's a huge support. I wouldn't be able to do this without him. He does things for me all the time ... little things. I'll say, I have a quiz this week that I have to do so, for the next five minutes these kids are your problem, and he says "Great" and I do it. If the kids come up to me, he says, "Let's go in the basement so Mom can do a quiz." I couldn't do these things without him.

\section{Emotional support}

Although physical (i.e., instrumental) supports were described as being appreciated, the emotional support partners shared seemed to have the largest impact in terms of reducing stress and helping mature students focus on school. This kind of support was reported by 26 participants. Robert fondly described the lengths his partner went to help him find a program that would excite him and the steps to take in order to be accepted. He explained:

She went through a lot of the programs with me that universities offered and we talked a lot about what my interests were and what she saw me being interested in and passionate about. So there was a lot of discussion back and forth about what I actually wanted to do. And I think it was with her encouragement that I did apply to the business program.

Other participants shared that their partner's emotional support was crucial to their mental well-being and confidence about being able to continue in school. Elsie said:

He's been nothing but supportive. Every time I say"I don't know if I can do this ... I don't know what the teacher expects," he's like, "Don't worry about it, you'll do fine, just sit back, put it aside for now, and go back tomorrow and take a look at it and you might understand what it is."

Joyce echoed Elsie's comments, noting how she depended on her partner to be there for her in various emotional ways, from checking in on her well-being to offering encouragement.

Just a lot of caring and ... general feedback on what I'm doing, that I shouldn't worry about it, that somebody in the family will take care of it. That relieves some of the stress. Some of the other emotional support is in the form of love and encouragement: "You can do this" if I feel down or [they are] concerned about my ability to handle the course load or do research for my papers, etc. He just says, "How can I help you, what can I do?" He takes some of the load off my shoulders and the stress. 


\section{Academic support}

Although not as commonly reported, 10 participants described having partners who could (or would) edit assignments or help them study. They described school as providing a context to learn from, and connect with, their partner as they continued with their academic studies. Trent said of his partner, "I've had her look over some of my assignments. She's a lot better writer than I am and she's really helped me improve my writing skills." Robert said that his partner had some knowledge in his particular area of study and would help him understand his course material when possible.

She is quite a bit younger than me ... and the courses had changed a drastic amount since I was there. [laughing] So she was able to guide me through it. I am sure that I could have figured it out myself, but it was helpful to have someone who was far more recently in high school to help me through it. Just because a lot of the topics were things that I didn't even take when I was in high school.

\section{Financial support}

Nine participants described feeling supported by their partners through financial avenues. It was quite common for participants to describe having to pull back their work hours (or stop working entirely) to accommodate their studies. As a result, mature students often described being less able (or temporarily unable) to be employed to contribute to their household finances. Trent was grateful that, when tuition payments were due, his partner helped pay for other bills to alleviate any potential financial stress.

At the beginning when I have to pay for the tuition ... I know she's always here to pay a little more... on her part in terms of the bills that we have so that I have enough funds for the tuition. So that's pretty helpful.

Another participant described the transition in her family home when she was no longer working and her husband was now completely responsible for their income. Lidia described being grateful that her partner was open to this possibility, otherwise she might not have been able to return to school at all.

Knowing that he was willing to take on the burden of being the sole breadwinner, because that had been my job, and I originally brought in the majority of the income. Considering he was willing to kind of live a lesser-type life and really supported me... Without it, I wouldn't have been able to go.

These two examples highlight a need for serious consideration of socioeconomic class in higher education, which is often ignored in adult education (Field \& Morgan-Klein, 2013). Partners were financially supportive of students returning to school, but this might not always be the case, and financial support might influence power differentials in a relationship. Although not a dominant theme in this research project, this is a worthwhile consideration for future research. 


\section{Recommendations for Support from Postsecondary Institutions}

In light of reported experiences in this study around relationships and their impact on academic success, there are several recommendations arising from the thematic analysis for postsecondary educational institutions regarding support that could be offered to partnered mature students. Specifically, participants discussed the importance of a) increasing awareness of issues unique to mature students, b) providing mature student counsellors and/or mentors,

c) having support groups, and d) having increased ease of access to supports.

\section{Increase awareness of issues unique to mature students}

Participants had a shared understanding that mature students face different challenges and experiences in their intimate and sexual relationships than individuals entering PSE directly from high school. In light of this, 10 participants shared a need for postsecondary institutions to consider their unique experiences when offering any form of support. Robert shared, "If there can be some kind of thing offered to students who aren't just coming straight out of high school because the dynamic, headspace, relationship status, home life, and everything for those people is so drastically different."

Specific suggestions for supports centred on including mature students' partners so they knew what to expect when they returned to school. Nora noted the importance of her family knowing what to expect when she returned to school, as she could not have anticipated the impact it would have on them. She said, "How is it going to impact my family? I don't know until I start. My husband or kids could use information, but what is it about the spouse going back to school that might be for them?" Finally, Raul indicated that information particularly related to changes mature students might expect in their family homes would be of value.

I certainly feel when you are applying for admission to an undergraduate program as a mature student, that there shouldn't just be literature that the undergraduates get in high school. I think it would be appropriate for mature students to receive literature saying that once you begin your studies, and manage your relationship and full-time work and courses at the same time, $x, y$ and $z$ will happen.

\section{Mature student counsellors and/or mentors}

Eleven participants suggested that, as a program of study continues, it would be helpful for postsecondary institutions to offer mature students counselling support for themselves and their partners. Participants suggested that this support come from either a professional counsellor/therapist or a mentor (i.e., another mature student who was more advanced in their degree). Hani described the potential benefit of having trained counsellors available for mature students' partners. "If your husbands and boyfriends can walk in to the guidance 
counsellor and say how much stress will be brought to this type of studies ... that might be a thing for others that might be helpful."

In addition to trained professionals, participants indicated that someone who was also a mature student might be a helpful resource to have access to for peer support about mature student issues. Lesley said:

Just someone I can connect with on a personal level because you might not always connect with someone in your program; just to be matched up with kind of the same dynamics, in relationships and life and ... I think that would have been really helpful.

Having a mentor was described as a more relaxed, or less formal, way of discussing issues faced by mature students with someone who might have gone through something similar. Loretta commented:

For me I think it would have been helpful to have had a one-on-one, like a mentor that I could just kinda hook up with and say, "Well, this is what's going on. How did you deal with it?"I don't think necessarily an info package or a PowerPoint or full session would have been as helpful as having someone to touch base with.

\section{Support groups}

Similar to the idea of meeting with a peer or having access to counselling, another resource suggested by nine participants was support groups where a group of mature students could meet to discuss their concerns and offer guidance. Candace shared:

Offering opportunities or [an] area for mature students to gather and having a safe space to talk where it's not intimidating, because sometimes when you walk into a room with 60 19-year-olds wearing UGGs [popular footwear], it can be a little awkward.

Donald indicated that having others to talk to who understood the particular concerns and stresses of mature students would be of value.

I imagine something like a support group or even some counselling that could be available where we can meet a counsellor and talk about some of the issues that might arise. I think that would be really helpful. A support group, where you can have get-togethers for like-minded mature students or, experiencing issues, you can bounce ideas off each other. I think that would be really helpful, seeing other people who are going through the same thing ... it could be different support groups focused on different areas of life. You know, one maybe having stress, maybe another one on how it will impact your relationship, so that kind of thing. 


\section{Increased ease of access to supports}

Three mature student participants indicated that in addition to having peer supports or counsellors, the way in which they could access these supports was important. Carissa described that she felt current supports catered toward more traditional students who were on campus more regularly. "I definitely feel the whole scheduling system is geared towards students who don't have obligations other than school. I know a lot work part-time and have other obligations, but the scheduling is not always helpful." Given that not all mature students were able to be on campus before or after classes, and because of previously described schedules that were busy and stressful, some participants said it would be helpful to be able to access supports in more creative, technological ways. Ana suggested:

If there was an option, they could do ... like counselling through Skype. I think that would be a huge benefit because, again, your schedules are different. When you are 20 and at school, your schedule is really determined by your class schedule and what your friends want to do. I think you have more time and freedom of resources, but the big thing I found is that too many depend on your time. So the easier you can fit something in, the greater the likelihood it will actually happen, as opposed to something that you think you should do but you just can't schedule in.

\section{Discussion}

Adult education, according to Houle (1996), "is the process by which men and women (alone, in groups, or in institutional settings) seek to improve themselves or their society by increasing their skill, knowledge, or sensitiveness; or it is any process by which individuals, groups, or institutions try to help men and women improve these ways" (p. 41). For this process to be effective, the education of adults requires educators and administrators to be open, supportive, and mindful of the various challenges adult learners face (MacFadgen, 2008). To this end, Nesbit (2005) realizes an interconnectedness between policy, teaching, learning, identity, and relationships between class, race, and gender that is necessary to support adult learners. For mature students, this interconnectedness creates a need for strong policies that meet their unique needs (Amaral \& Magalhães, 2009), inclusive teaching practice (Toynton, 2005), a set of different learning habits (Hoult, 2006), mature student identity construction (Baxter \& Britton, 2001), and a close awareness of how class, race, and gender all impact the lives of mature students (Maher, 2001; Mathers \& Parry, 2009). Since Gouthro (2002) states that "the homeplace is linked to the individual's sense of identity, forms a centre of interpersonal relationships, and is also a site of paid and unpaid labour" (p. 7), through this research project we add that intimacy and relationship satisfaction in the homeplace is also an important consideration in this interconnectedness. 
Intimacy and relationship satisfaction remains a largely unexplored area in the mature student literature, although relationships with partners in general are centrally important to adult learners, and in particular, to the lives of women (Stalker, 2001). The findings from the current study suggest there is a bidirectional impact between relationship satisfaction and academic success. Participants in this study were more likely to report some of the negative impacts that school had on their relationships, including having less time to spend with their partners, not having time or energy for intimacy and sex, and having difficulty navigating changing roles and chores in their family home. Nevertheless, mature students also report positive impacts on intimate relationships after returning to school, including increased self-esteem, appreciating their partner's support, and having new opportunities to bond with their partner. This research reveals that the study participants were resilient in their efforts to work through the additional demands on them as mature students and maintain a stable relationship. Similar to Vaccaro and Lovell's (2010) findings, study participants were inspired by their partners to continue their education. Supportive partners were described as helping to reduce the negative impact of academic stress (through instrumental, emotional, academic and financial avenues), which arguably improves academic performance.

The current study findings align with the limited research on the topic. In an earlier study of mature students and intimate relationships, van Rhijn and colleagues (2015) similarly reported that mature students had less time to spend with their partner and felt the stress from school negatively impacted their relationship. These negative impacts have also been reported in other research (e.g., Brannock et al., 2000; Fuenfhausen \& Cashwell, 2013; Giancola et al., 2009; Meehan \& Negy, 2003).

The findings also offer support for Schnarch's (2001) theory of intimacy. Specifically, when mature students described feeling too separate from their partners (i.e., school demands were so demanding they were unable to engage in desired couple activities), their intimacy, including their desire for sexual connection, decreased. However, some mature students also described the positive impacts of pursuing their own interests and goals, which they described as increasing intimacy in their relationship, thereby offering support for Schnarch's description of differentiation (2001). Considering these positive and negative impacts, mature students may benefit from aiming to create a balance between the time spent pursuing their individual interests by focusing on school demands while also trying to find time to connect with their partners to enhance their overall level of intimacy (Crawford, Houts, Huston, \& George, 2002; Voorpostel, van der Lippe, \& Gershuny, 2009). Although school demands were often described as coming first, decreased relationship satisfaction and intimacy were found to ultimately hinder academic performance and success, suggesting that making time for intimate relationships may actually improve academic performance.

The current study was able to examine the bidirectional relationship between returning to school and intimate relationships, rather than only inquiring about school's impact on relationships. This study suggests there may be a more complex relationship between intimate 
relationships and academic success among mature students. Recognition that partner relationships also impact academic success through the provision of support in various ways (e.g., physical, emotional, financial, academic) relates to previous work linking relationship satisfaction to academic success (Lundberg et al., 2008; Shollenberger, 2001), and social support from partners influencing study strategies (Kahu et al., 2014).

\section{Strengths and Limitations}

The current study adds to the literature on mature student experiences by exploring a poorly understood contributing factor (i.e., relationship dynamics) on academic performance, and uncovering that many mature students describe meaningful connections between their relationship quality and academic performance. Participants were recruited from a number of different Canadian universities in southern Ontario, thereby increasing the applicability of the findings to a broader population than would be achieved from including participants from only one university. Additionally, the study participants represented a range of mature student demographics; specifically, there was a fairly even spread of men and women, part-time and full-time students, those with children and those without, and so forth. This diversity allows for the findings to be considered as applicable to a diverse group of mature students. Finally, participants were asked to consider their intimate relationships quite broadly, being asked about their relationship and sexual satisfaction, the effects related to returning to school, and how their partner influenced their experiences. While this provided a unique lens through which to consider intimacy in their relationships, participants did not differentiate between sexual satisfaction and relationship satisfaction in their interviews; therefore, we were unable to disentangle these concepts in our analysis.

Balancing these strengths, some noteworthy limitations should be considered when interpreting these findings. Although the participants represented a diverse group of mature student demographics, it should be restated that all of the participants in the current study identified as heterosexual and cisgender. Mature students who identify as lesbian, gay, bisexual, transgender, or queer (LGBTQ) may face additional or different experiences that are of equal value and also important to understand. Future research inquiring about mature students' intimate relationships within the LGBTQ community is recommended. Additionally, our study focused on the experiences of partnered mature students and did not include the experiences of sole parents (Hook, 2015). We recommend that parents who are not partnered be included in future mature student research.

In addition, the interviews were conducted over the phone, which may have led to slightly different findings than if the interviews were conducted face to face. Some researchers have concluded that there are no differences between face-to-face and telephone interviews and that, in addition to cost savings, telephone interviews allow for better access to hard-to-reach populations while generating the same quantity and quality of data (Sturges \& Hanrahan, 2004). Others have found that there is a reduction in both the quantity and quality of data, and 
they suggest strategies for enhancing telephone interviews, including finding ways to facilitate establishing rapport and being more conscious of encouraging elaboration if responses are more concise (Irvine, 2011). For this study, being able to interview from a distance was important given distance considerations and the busy lives of the participants. It is possible that, on one hand, the phone-based interviews may have provided increased perceptions of anonymity, perhaps allowing participants to discuss their relationships and sexual experiences in more detail. Alternatively, this form of interviewing makes it difficult to perceive non-verbal cues or create the same connection that could be made face to face. It may be that with a reduced ability to establish rapport, participants may have been less inclined to discuss personal details than in person. Of note, while participants were very forthcoming about the degree to which their relationship satisfaction was impacting, or impacted by, their studies, sexual satisfaction was something that not all participants described or was described in less detail. It could be that sexual satisfaction was less applicable to mature students' academic performance. It could also be that participants did not feel comfortable enough to share these more personal details.

\section{Concluding Thoughts and Implications}

This project highlights the importance of intimate partners to mature students' experiences in their studies as well as in their relationships. This project may assist university policy makers in considering the different kinds of supports and resources that may be useful to mature students in light of challenges surrounding partner relationships and sexuality. To help mature students' partners support their academic endeavours, mature students said it would be helpful for them to be better informed about what to expect with their partner returning to school (e.g., including partners in orientation meetings before school starts so they have a better idea of what to expect). It may also be important to offer couple counselling sessions throughout the school year, when stress could have more negative impacts on these individuals' mental health and relationship. Orientation meetings and counselling supports are already available resources on many postsecondary campuses; however, most mature students felt either unaware of these resources or uncertain whether their specific needs could be adequately addressed given that these supports typically target traditional students (i.e., 18- to 25-year-olds without long-term partners). Increasing the awareness of supports that are already available, and slightly adjusting them to address mature students' needs could be an affordable and helpful way to encourage academic success among mature students in intimate partnerships. 


\section{References}

Amaral, A., \& Magalhães, A. (2009). Between institutional competition and the search for equality of opportunities: Access of mature students. Higher Education Policy, 22, 505-521.

Baxter, A., \& Britton, C. (2001). Risk, identity and change: Becoming a mature student. International Studies of Sociology of Education, 11(1), 87-104.

Bodenmann, G., Ledermann, T., \& Bradbury, T. (2007). Stress, sex, and satisfaction in marriage. Personal Relationships, 14, 551-569.

Brannock, R., Litten, M. J., \& Smith, J. (2000). The impact of doctoral study on marital satisfaction. Journal of College Counseling, 3(2), 123-130.

Braun, V., \& Clarke, V. (2006). Using thematic analysis in psychology. Qualitative Research in Psychology, 3, 77-101. doi: 10.1191/1478088706qp063oa

Cramer, D. (2004). Emotional support, conflict, depression, and relationship satisfaction in a romantic partner. Journal of Psychology, 138(6), 532-542. doi: 10.3200/JRLP.138.6.532-542

Crawford, D. W., Houts, R. M., Huston, T. L., \& George, L. J. (2002). Compatibility, leisure, and satisfaction in marital relationships. Journal of Marriage and Family, 64, 433-449.

Diener, E., \& Seligman, M. E. P. (2002). Beyond money: Toward an economy of well-being. Psychological Science in the Public Interest, 5(1), 1-31.

Duxbury, L., Lyons, S., \& Higgins, C. (2008). Too much to do, and not enough time: An examination of role overload. In K. Korabik, D. S. Lero, \& D. L. Whitehead (Eds.), Handbook of Work-Family Integration: Research, Theory, and Best Practices (pp. 125-140). San Diego, CA: Elsevier.

Fernald, D. H., \& Duclos, C. W. (2005). Enhance your team-based qualitative research. Annals of Family Medicine, 3(4), 360-364.

Field, J., \& Morgan-Klein, N. (2013). Reappraising the importance of class in higher education entry and persistence. Study of the Education of Adults, 45(2), 162-176.

Fuenfhausen, K. K., \& Cashwell, C. S. (2013). Attachment, stress, dyadic coping, and marital satisfaction of counseling graduate students. Family Journal: Counseling and Therapy for Couples and Families, 21(4), 364-370. doi: 10.1177/1066480713488523

Galvin, C. R. (2006). Research on divorce among postsecondary students: Surprisingly missing. Family Journal, 14(4), 420-423. doi: 10.1177/1066480706291041

Giancola, J. K., Grawitch, M. J., \& Borchert, D. (2009). Dealing with the stress of college: A model for adult students. Adult Education Quarterly, 59(3), 246-263. doi: $10.1177 / 0741713609331479$

Gilbert, M. (1982). The impact of graduate school on the family: A systems view. Journal of College Student Personnel, 23, 128-135. 
Gold, J. M. (2006). Exploring marital satisfaction among graduate students: Implications for service delivery. Family Journal, 14(4), 417-419. doi: 10.1177/1066480706290979

Goode, W. (1960). A theory of role strain. American Sociological Review, 25, 483-496.

Gouthro, P. (2002). What counts? Examining academic values and women's life experiences from a critical feminist perspective. Canadian Journal for the Study of Adult Education, 16(1), 1-19.

Hook, G. A. (2015). Recognition and accountability: Sole parent postgraduates in university conditions. Gender and Education, 27(2), 114-130. doi: 10.1080/09540253.2014.992301

Houle, C. O. (1996). The design of education (Rev. ed.). San Francisco, CA: Jossey-Bass.

Hoult, E. (2006). Learning support: A guide for mature students. New York, NY: Sage.

Huston-Hoburg, L., \& Strange, C. C. (1986). Spouse support among male and female returning adult students. Journal of College Student Personnel, 27(5), 388-393.

Irvine, A. (2011). Duration, dominance and depth in telephone and face-to-face interviews: A comparative exploration. International Journal of Qualitative Methods, 10(3), 202-220.

Kahu, E. R., Stephens, C., Zepke, N., \& Leach, L. (2014). Space and time to engage: Mature-aged distance students learn to fit study into their lives. International Journal of Lifelong Education, 33(4), 523-540. doi: 10.1080/02601370.2014.884177

Kerr, A. (2011). Adult learners in Ontario postsecondary institutions. @ Issue Paper No. 9. Toronto, ON: Higher Education Quality Council of Ontario.

Lowe, J., \& Gayle, V. (2007). Exploring the work/life/study balance: The experience of higher education students in a Scottish further education college. Journal of Further and Higher Education, 31(3), 225-238. doi: 10.1080/03098770701424942

Lundberg, C. A., McIntire, D. D., \& Creasman, C. T. (2008). Sources of social support and self-efficacy for adult students. Journal of College Counseling, 11, 58-72.

MacFadgen, L. (2008). Mature students in the persistence puzzle: An exploration of the factors that contribute to mature students' health, learning, and retention in post-secondary education. Retrieved from http://www.ccl-cca.ca/NR/rdonlyres/65C42165-C7AA-431F-841F1B1513BF272A/0/MacFadgenFinalAL2006.pdf

Maher, F.A. (2001). Women's studies in England: Mature women students and their educational vision. Gender and Education, 13(1), 7-23.

Markle, G. (2015). Factors influencing persistance among nontraditional university students, Adult Education Quarterly, 65(3), 267-285. doi: 10.1177/0741713615583085

Mathers, J., \& Parry, J. (2009). Why are there so few working-class applicants to medical schools? Learning from the success stories. Medical Education, 43, 219-228.

Meehan, D., \& Negy, C. (2003). Undergraduate students' adaptation to college: Does being married make a difference? Journal of College Student Development, 44(5), 670-690. doi: $10.1353 /$ csd.2003.0055 
Nesbit, T. (2005). Social class and adult education. New Directions for Adult and Continuing Education, 106, 5-14. doi: 10.1002/ace.174

Norton, L. S., Thomas, S., Morgan, K., Tilley, A., \& Dickins, T. E. (1998). Full-time studying and longterm relationships: Make or break for mature students? British Journal of Guidance and Counselling, 26(1), 75-88.

Schnarch, D. (2001). The therapist in a crucible: Early developments in a new paradigm of sexual and marital therapy. In S. H. McDaniel, D.-D. Lusterman, \& C. L. Philpot (Eds.), Casebook for Integrating Family Therapy: An Ecosystemic Approach (pp. 43-56). Washington, DC: American Psychological Association.

Scott, C., Burns, A., \& Cooney, G. (1996). Reasons for discontinuing study: The case of mature female students with children. Higher Education, 31, 233-253.

Shollenberger, M. A. (2001). Increasing marital adjustment in graduate students and their spouses through relationship enhancement. Unpublished doctoral dissertation. Virginia Polytechnic Institute and State University, Blacksburg, VA.

Stalker, J. (2001). Misogyny, women, and obstacles to tertiary education: A vile situation. Adult Education Quarterly, 51(4), 288-305.

Statistics Canada. (2014). Labour Force Survey [Public use microdata files]. Retrieved from http://www.search2.odesi.ca

Sturges, J. E., \& Hanrahan, K. J. (2004). Comparing telephone and face-to-face qualitative interviewing: A research note. Qualitative Research, 4(1), 107-118.

doi: $10.1177 / 1468794104041110$

Sweet, S., \& Moen, P. (2007). Integrating educational careers in work and family: Women's return to school and family life quality. Community, Work and Family, 10(2), 231-250. doi: 10.1080/13668800701270166

Toynton, R. (2005). Degrees of disciplinarity in equipping mature students in higher education for engagement and success in lifelong learning. Active Learning in Higher Education, 6(2), 106-117.

van Rhijn, T. M., Murray, S. H., \& Mizzi, R. C. (2015). A mixed-methods inquiry into the intimate practices of partnered mature students and influences on relationship, sexual, and school satisfaction. Canadian Journal of Higher Education, 45(2), 116-133.

Vaccaro, A., \& Lovell, C. D. (2010). Inspiration from home: Understanding family as key to adult women's self-investment. Adult Education Quarterly, 60(2), 161-176. doi: 10.1177/0741713609336111

Voorpostel, M., van der Lippe, T., \& Gershuny, J. (2009). Trends in free time with a partner: A transformation of intimacy? Social Indicators Research, 93(1), 165-169. doi: 10.1007/ s11205-008-9383-8 


\section{Biographies}

Tricia van Rhijn is an assistant professor in the Department of Family Relations and Applied Nutrition at the University of Guelph. Her research interests include early childhood education and care, family relations, work-life integration, and the experiences of non-traditional students in formal postsecondary education, in particular mature students and student parents.

Tricia van Rhijn est professeure adjointe au Department of Family Relations and Applied Nutrition (Département des relations familiales et de la nutrition appliquée) de l'Université de Guelph. Parmi ses sujets de recherche, on trouve l'éducation préscolaire et la garde d'enfants, les rapports familiaux, l'intégration travail-vie et les expériences d'étudiants non traditionnels en éducation post-secondaire formelle, en particulier les étudiants majeurs et les parents d'étudiants.

Sarah Hunter Murray is an individual, couple, and family therapist in Winnipeg, Manitoba, and a member of the American Association of Marriage and Family Therapists. She specializes in clinical issues related to intimacy and sexuality. Her research focuses on gaining a better understanding of sexual desire, sexual satisfaction, and relationship satisfaction, primarily in longer-term relationships.

Localisée à Winnipeg, au Manitoba, Sarah Hunter Murray est thérapeute individuelle, conjugale et familiale, ainsi que membre de l'American Association of Marriage and Family Therapists (Association américaine des thérapeutes conjugaux et familiaux). Elle se spécialise dans les sujets cliniques liés à la sexualité et à l'intimité. Ses recherches portent surtout sur l'atteinte d'une meilleure compréhension du désir sexuel, de la satisfaction sexuelle et de la satisfaction relationnelle, principalement dans les relations à long terme.

Robert Mizzi is an assistant professor in the Department of Educational Administration, Foundations and Psychology at the University of Manitoba. His research interests largely focus on educator work and welfare from the perspectives of educational administration, adult education, and sexuality and gender studies.

Robert Mizzi est professeur adjoint au Department of Educational Administration, Foundations and Psychology (Département de la psychologie, de la gestion et des fondements de l'éducation) à l'Université du Manitoba. Ses sujets de recherche portent principalement sur le travail et le bien-être de l'éducateur du point de vue de l'administration éducative, de l'éducation permanente, et des études sur la sexualité et les genres. 